\title{
Efeito de Diferentes Níveis de Proteína Bruta na Ração sobre o Desempenho e as Características de Carcaça de Cordeiros Terminados em Creep Feeding ${ }^{1}$
}

\author{
Jessé Siqueira Ortiz², Ciniro Costa ${ }^{3}$, Cledson Augusto Garcia ${ }^{4}$, Liciana Vaz de Arruda Silveira ${ }^{5}$
}

\begin{abstract}
RESUMO - O experimento foi realizado com os objetivos de avaliar o efeito dos níveis de proteína bruta (15, 20 e 25\%) na ração concentrada sobre o desempenho e as características de carcaça de cordeiros Suffolk alimentados em creep feeding e analisar economicamente esse sistema de produção. Foram utilizados 15 cordeiros inteiros, nascidos de partos simples, alimentados ad libitum com as rações experimentais duas vezes ao dia. Estimaram-se o consumo de médio diário de ração, pelo cálculo da quantidade fornecida e das sobras; o ganho de peso, pela pesagem dos animais a cada 14 dias; o peso vivo ao abate (PVA) dos cordeiros em jejum (16 horas); e o rendimento de carcaça quente, após abate e evisceração. O ganho médio diário foi influenciado pelos níveis de proteína, quando considerada a idade de abate como covariável. Não houve efeito significativo dos níveis de proteína sobre as características de carcaça. No sistema de alimentação e terminação de cordeiros Suffolk em creep feeding, a ração deve ser balanceada com $25 \%$ de proteína bruta, uma vez que esse nível proporcionou maior ganho de peso médio diário e não alterou as características de carcaça.
\end{abstract}

Palavras chave: comedouro seletivo, idade de abate, ganho diário, ovinos

\section{Effects of Feeding Different Crude Protein Levels on Production and Carcass Traits of Suffolk Lambs in Creep Feeding}

\begin{abstract}
This trial was carried out to evaluate the effects of different concentrate crude protein levels (15, 20 or 25\%) on production and carcass traits of Suffolk lambs in creep feeding. An economical analysis of the production system was also performed. Fifteen single birth lambs fed ad libitum twice a day were used in this study. The average daily intake was measured by subtracting the orts from the amount of feed offered to the animals. Lambs were weighed every fourteen days to determine body weight gain. To measure slaughter body weight (SW) animals were fasted for $16 \mathrm{~h}$ and then weighted. After evisceration both hot carcass weight and yield were obtained. To determine cold carcass yield and cooling losses, carcasses were placed in a refrigerator at $5^{\circ} \mathrm{C}$ for 24 hours and weighted again. The different concentrate crude protein levels affected the daily weight gain only when the slaughter age was used as the covariable. Conversely, crude protein levels did not significantly change carcass traits in the present trial. It can be concluded that the concentrate with $25 \%$ of crude protein is recommended to Suffolk lambs in creep feeding because of the higher daily weight gain and maintenance of carcass traits.
\end{abstract}

Key Words: creep feeding, daily weight gain, sheep, slaughter age

\section{Introdução}

Os cordeiros, desde que atendidas suas exigências nutricionais, constituem a categoria ovina que apresenta maior eficiência para ganho de peso e qualidade de carcaça nos primeiros meses de vida. Portanto, é necessário o correto manejo nutricional logo nos primeiros dias de vida, destacando-se a utilização do creep feeding, que consiste na suplementação dos animais com alimento concentrado em local inacessível às ovelhas.

Segundo Bueno et al. (2000), os cordeiros da raça Suffolk apresentam carcaças com pesos adequados ao padrão de consumo da região Centro-Sul do Brasil, com boa deposição de tecidos muscular e adiposo e, quando criados em creep feeding, peso vivo ao abate variando de 26 a $32 \mathrm{~kg}$ (Monteiro et al., 2000).

O creep feeding é uma prática alimentar essencial para os sistemas intensivos de produção de cordeiros, pois proporciona crescimento acelerado, promovendo expressiva diminuição da idade de abate. O acesso ao creep feeding na fase inicial é de grande importância para adaptar os cordeiros à alimentação sólida e favorecer o funcionamento do rúmen, mesmo que com pequena quantidade (Neres, 2000).

\footnotetext{
${ }^{1}$ Projeto financiado pela Universidade de Marília (UNIMAR) e FMVZ - UNESP, Botucatu - SP.

2 Zootecnista autônomo e Mestre pela FMVZ - UNESP, Botucatu - SP (jesseso@uol.com.br).

3 Professor do Departamento de Melhoramento e Nutrição Animal - FMVZ - UNESP, Botucatu - SP.

4 Professor do Dep. de Zootecnia da FCA e do Prog. de Pós Graduação - UNIMAR, Marilia - SP (cgarcia-ca@unimar.br).

5 Professora do Departamento de Bioestatística - UNESP, Botucatu - SP.
} 
O correto manejo alimentar dos cordeiros lactentes está relacionado também à quantidade de leite produzida pelas ovelhas, pois o leite é fundamental no ganho de peso dos cordeiros até o primeiro mês de vida (Silva et al, 2002), quando os animais passam a ingerir maiores quantidades de alimentos sólidos em razão do aumento de suas exigências nutricionais (Garcia, 2002).

A melhoria no nível nutricional dos cordeiros, em termos de energia e proteína, pode elevar os custos de produção, motivo pelo qual muitos pesquisadores têm avaliado o uso de ingredientes alternativos na alimentação animal. Entretanto, geralmente a formulação de rações é embasada em tabelas de exigências nutricionais estrangeiras, de países de clima temperado, e, portanto, não são apropriadas para o uso em regiões de clima tropical (Carvalho et al., 1998). As recomendações nutricionais do NRC (1985) para cordeiros com crescimento moderado, pesando entre 10 e $30 \mathrm{~kg}$, são de aproximadamente 17\% de PB e 2,8 Mcal EM/kg MS. Garcia (2002) testou rações isoprotéicas com $18 \%$ de PB e níveis crescentes de energia metabolizável (2,6; 2,8 e 3,0 Mcal EM/kg MS) para cordeiros em creep feeding e concluiu que o nível de energia que proporcionou os melhores resultados para desempenho, peso e rendimento dos cortes comerciais, composição tecidual e musculosidade da carcaça foi de 3,0 Mcal EM/kg MS.

Os teores de proteína na dieta podem influenciar o desenvolvimento dos animais, aumentando o consumo de matéria seca e melhorando a conversão alimentar e o ganho de peso (Fluharty \& McClure, 1997; Zundt et al., 2002).

Entre os suplementos protéicos mais utilizados para ruminantes jovens, o farelo de soja é o que apresenta boa aceitabilidade e balanceamento em aminoácidos. Sua fração de proteína não-degradável no rúmen possui um escape de nitrogênio para o intestino em torno de 25\% (NRC, 1996). Essa fração degradável aumenta o fornecimento de proteína metabolizável pelo maior fluxo de proteína microbiana (Milton et al., 1997).

Zundt et al. (2002), avaliando os níveis de 12, 16, 20 e $24 \%$ de proteína bruta na dieta de cordeiros confinados com 5 meses de idade, observaram melhoria na conversão alimentar e no ganho de peso dos animais que receberam a dieta com os maiores níveis de proteína, porém,o maior retorno econômico foi obtido com a ração contendo 12\% PB.

Assim, nos sistemas de produção mais intensivos, é necessária a adoção de tecnologias que permitam eficiência e economicidade (Reis et al., 2000) para redução dos custos da alimentação, com a formulação de dietas que possibilitem máxima eficiência na produção de carne e custo mínimo de produção (Susin et al., 2000).

Este trabalho foi realizado com os objetivos de avaliar o desempenho e as características de carcaça de cordeiros Suffolk alimentados com rações balanceadas com três níveis de proteína (15, 20, 25\% PB) e analisar economicamente o sistema de produção e terminação em creep feeding.

\section{Material e Métodos}

O experimento foi realizado no Setor de Ovinocultura da Fazenda Experimental "Marcelo Mesquita Serva”, pertencente à Faculdade de Ciências Agrárias da Universidade de Marília (UNIMAR), em Marília, SP. Utilizaram-se 15 cordeiros machos nãocastrados, mestiços Suffolk, grau de sangue 15/16, nascidos de partos simples, terminados em creep feeding, alimentados ad libitum com as rações experimentais duas vezes ao dia (Tabela 1 ).

Adotou-se o delineamento experimental inteiramente casualizado, com três tratamentos (15; 20; 25\% de PB) e cinco repetições.

Os valores médios obtidos nas análises químicas dos ingredientes e rações experimentais encontram-se na Tabela 2.

No terço final de gestação, as ovelhas permaneceram em pastejo, porém recebendo feno de tifton-85 (Cynodon spp.) à vontade e suplementação com ração concentrada com $16 \%$ de $\mathrm{PB}$ e $77 \%$ de NDT, constituída de grãos de milho moído, farelo de trigo e farelo de soja, na proporção de $1 \%$ do peso vivo, com base na matéria seca, visando atender aos requerimentos nutricionais dessa fase (NRC, 1985).

Após o parto, as ovelhas de parto simples foram distribuídas aleatoriamente, com seus respectivos cordeiros em piquetes de estrela branca (Cynodon plectostachyus). Em decorrência da concentração de parições no período de inverno, houve pequena disponibilidade de forragem e baixa qualidade da matéria seca. Desta forma, os lotes foram submetidos ao sistema de pastejo alternado e à suplementação com feno de tifton 85 (Cynodon spp.), na mesma proporção de ração concentrada no terço final de gestação.

Os cordeiros foram pesados e numerados logo após o nascimento. Nos primeiros sete dias de vida, 
foram mantidos durante 4 horas na área cercada do creep feeding, com livre acesso à água, para adaptação às instalações e contato inicial com o alimento sólido. Foram efetuadas pesagens diárias das quantidades de ração, fornecidas duas vezes ao dia, pela manhã e à tarde, e das sobras, para estimativa do consumo médio diário dos cordeiros em cada tratamento.

Os cordeiros receberam uma primeira dose da vacina contra clostridioses aos 14 dias de vida e reforço após 30 dias de idade. O monitoramento foi efetuado segundo metodologia descrita por Matos \&

Tabela 1 - Composição percentual das rações experimentais com três níveis de proteína bruta

Table 1 - Ingredient composition (\%) of experimental diets with three crude protein levels

\begin{tabular}{lccc}
\hline $\begin{array}{l}\text { Ingrediente } \\
\text { Ingredient }\end{array}$ & $15 \%$ & $20 \%$ & $25 \%$ \\
\hline $\begin{array}{l}\text { Feno coastcross } \\
\begin{array}{l}\text { Coast cross hay } \\
\text { Farelo de soja }\end{array}\end{array}$ & 10,00 & 10,00 & 10,00 \\
$\begin{array}{l}\text { Soybean meal } \\
\text { Farelo de trigo }\end{array}$ & 15,86 & 29,26 & 42,65 \\
$\begin{array}{l}\text { Wheat bran } \\
\text { Milho moído }\end{array}$ & 10,00 & 10,00 & 10,00 \\
$\begin{array}{l}\text { Ground corn } \\
\text { Salmineral }\end{array}$ & 60,14 & 46,74 & 33,35 \\
$\begin{array}{l}\text { Mineral salt } \\
\text { Núcleo vitamínico }\end{array}$ & 2,00 & 2,00 & 2,00 \\
$\begin{array}{l}\text { Vitamin premix } \\
\text { Total }\end{array}$ & 2,00 & 2,00 & 2,00 \\
\hline
\end{tabular}

Matos (1988), pela contagem do número de ovos por grama de fezes (OPG), em amostras coletadas semanalmente diretamente da ampola retal das ovelhas e dos cordeiros. A everminação foi feita sempre que a contagem de OPG estivesse acima de 500.

A cada 14 dias, foi efetuada a pesagem dos cordeiros pela manhã, para determinação do ganho médio diário de peso. Quando os cordeiros atingiram peso vivo final aproximado de $28 \mathrm{~kg}$, calculou-se o ganho médio de peso no último intervalo de 14 dias e determinou-se a data de abate.

Na véspera do abate, os cordeiros foram pesados, para registro do peso vivo final (PVF), e à tarde, aproximadamente às $17 \mathrm{~h}$, foram separados das mães, sendo alimentados exclusivamente com dieta hídrica, durante 16 horas, para cálculo do peso vivo ao abate (PVA), e, em seguida, foram abatidos. Após o abate, os animais foram eviscerados e o aparelho gastrintestinal foi esvaziado, retirando-se o conteúdo digestório (CD) para obtenção do peso de corpo vazio (PCV), em que PCV = PVA - CD.

Terminada a evisceração, o peso da carcaça quente (PCQ) foi registrado e as carcaças foram levadas para câmara de refrigeração a $5^{\circ} \mathrm{C}$, onde permaneceram por 24 horas penduradas pelas articulações tarso metatarsianas. Em seguida, procedeu-se à pesagem para obtenção do peso da carcaça fria (PCF), que serviu como referencial para o cálculo da perda de peso por resfriamento $(\mathrm{PR}) \%=(\mathrm{PCQ}-$ PCF/PCQ) X 100. Também foram obtidas outras

Tabela 2 - Composição química, na matéria seca, dos ingredientes e das rações experimentais com três níveis de proteína bruta

Table 2 - Chemical composition of ingredients and experimental diets with three crude protein levels, dry matter basis

\begin{tabular}{lccccccccc}
\hline $\begin{array}{l}\text { Ingredient } \\
\text { Ingredient }\end{array}$ & $\mathrm{MS}$ & $\mathrm{PB}$ & $\mathrm{EE}$ & $\mathrm{MM}$ & $\mathrm{FDN}$ & $\mathrm{FDA}$ & $\begin{array}{c}\text { Lignina } \\
\text { Lignin }\end{array}$ & $\begin{array}{c}\text { Celulose } \\
\text { Cellulose }\end{array}$ & $\begin{array}{c}\mathrm{EM} \\
M E\end{array}$ \\
\hline $\begin{array}{l}\text { Feno coastcross } \\
\text { Coastcross hay }\end{array}$ & 91,25 & 10,66 & 3,34 & 2,24 & 74,93 & 41,44 & 7,23 & 30,24 & 2,25 \\
$\begin{array}{l}\text { Farelo de soja } \\
\text { Soybean meal }\end{array}$ & 88,57 & 51,76 & 2,3 & 6,37 & 12,85 & 13,68 & 2,22 & 9,84 & 3,59 \\
$\begin{array}{l}\text { Farelo de trigo } \\
\text { Wheat bran }\end{array}$ & 89,18 & 18,37 & 4,79 & 4,25 & 42,39 & 13,74 & 5,38 & 8,32 & 2,60 \\
$\begin{array}{l}\text { Milho moído } \\
\text { Ground corn }\end{array}$ & 88,06 & 9,66 & 4,1 & 0,57 & 18,45 & 4,16 & 1,11 & 2,11 & 3,48 \\
Nível de proteína (\%) & & & & & & & & & \\
$\begin{array}{l}\text { Protein level (\%) } \\
\text { 15 }\end{array}$ & & & & & & & & & \\
20 & 85,05 & 16,92 & 3,64 & 2,00 & 24,87 & 10,19 & 2,28 & 6,69 & 3,31 \\
25 & 85,12 & 22,56 & 3,40 & 2,78 & 24,12 & 11,47 & 2,43 & 7,72 & 3,32 \\
\hline
\end{tabular}

MS: matéria seca; PB: proteína bruta; EE: extrato etéreo; MM: matéria mineral; FDN: fibra detergente neutro; FDA: fibra detergente ácido; EM: energia metabolizável (Mcal $/ \mathrm{kg}$ ).

DM: dry mater; CP: crude protein; EE: ether extract; MM: mineral matter; NDF: neutral detergent fiber; ADF: acid detergent fiber; ME: metabolizable energy (Mcal/kg). 
variáveis por cálculo: rendimento de carcaça quente $(\mathrm{RCQ}) \%=(\mathrm{PCQ} / \mathrm{PVA}) \times 100$; rendimento da carcaça fria ou rendimento comercial $(\mathrm{RCF}) \%=(\mathrm{PCF} /$ $\mathrm{PVA}) \times 100$ e rendimento verdadeiro $(\mathrm{RV}) \%=(\mathrm{PCQ} /$ PCV) x 100.

Para o ganho médio diário, efetuaram-se a análise de variância, incluindo-se o efeito fixo da ração e a covariável idade ao abate, e os estudos das regressões polinomiais, de acordo com os três níveis de proteína. Para as demais variáveis, realizaram-se a análise de variância, considerando-se somente o efeito fixo da ração, e o estudo das regressões polinomiais segundo os três níveis de proteína. As análises foram realizadas pelo procedimento GLM do SAS (1985).

\section{Resultados e Discussão}

Os resultados obtidos neste experimento indicaram diminuição na idade de abate, conforme se aumentaram os níveis protéicos da dieta, por melhorar o ganho de peso médio diário dos cordeiros (Tabela 3).

Os valores médios para peso ao nascer, consumo médio diário, ganho médio diário e idade de abate são apresentados na Tabela 3. Os pesos ao nascer dos cordeiros dos três tratamentos foram próximos, conferindo homogeneidade aos lotes.

O consumo diário de ração entre os três grupos não foi analisado estatisticamente por não haver os dados de consumo individual para cada cordeiro. Entretanto, o consumo médio diário de ração por animal foi de 0,$197 ; 0,269$ e 0,386 kg MS/dia para os lotes com 15; 20 e $25 \%$ de $\mathrm{PB}$, respectivamente. O aumento da ingestão de MS de acordo com os níveis de proteína nas rações também foi observado por outros autores (Meherez \& Orskov, 1978; Fluharty \& McClure, 1997).

Possivelmente, as modificações nas quantidades dos ingredientes para ajuste dos níveis de proteína nas rações conferiram maior digestibilidade à ração contendo $25 \%$ de PB, confirmando os resultados obtidos por Zundt et al. (2001), que, ao testarem níveis crescentes de PB na ração de cordeiros em confinamento, verificaram que os valores de digestibilidade de proteína bruta e de carboidratos não-estruturais aumentaram com os níveis protéicos.

Entretanto, Zundt et al. (2002), avaliando níveis crescentes $(12,16,20,24 \%)$ de $\mathrm{PB}$ na ração de cordeiros em confinamento, não registraram aumento no consumo de alimentos com a elevação dos níveis
Tabela 3 - Médias e coeficientes de variação (CV\%) para peso ao nascer, consumo médio diário de ração, ganho médio diário e idade de abate de cordeiros Suffolk alimentados com três níveis de proteína bruta

Table 3 - Mean and coefficients of variation (CV\%) of birth weight, daily intake of concentrate, daily weight gain and slaughter age of Suffolk lambs fed three crude protein levels

\begin{tabular}{lcccc}
\hline \multirow{2}{*}{$\begin{array}{l}\text { Variável } \\
\text { Variable }\end{array}$} & \multicolumn{3}{c}{$\begin{array}{c}\text { Nível de proteína (\% PB) } \\
\text { Protein level (\% CP) }\end{array}$} & \\
\cline { 2 - 4 } & 15 & 20 & 25 & \\
\hline $\begin{array}{l}\text { Peso ao nascer (kg) } \\
\text { Birth weight (kg) }\end{array}$ & $3,77^{\mathrm{a}}$ & $4,80^{\mathrm{a}}$ & $4,37^{\mathrm{a}}$ & 17,72 \\
$\begin{array}{l}\text { Consumo diário de } \\
\text { ração (kg/MS) }\end{array}$ & 0,197 & 0,269 & 0,386 & \\
$\begin{array}{l}\text { Daily intake of concentrate } \\
\text { kg/DM) }\end{array}$ & & & & \\
$\begin{array}{l}\text { Ganho de peso médio } \\
\text { diário (kg/dia) }\end{array}$ & $0,37^{\mathrm{b}}$ & $0,36^{\mathrm{b}}$ & $0,41^{\mathrm{a}}$ & 4,91 \\
$\begin{array}{l}\text { Daily weight gain (kg/day) } \\
\begin{array}{l}\text { Idade de abate (dias) } \\
\text { Slaughter age (days) }\end{array}\end{array}$ & $65,60^{\mathrm{a}}$ & $67,00^{\mathrm{a}}$ & $60,60^{\mathrm{a}}$ & 15,47 \\
\hline
\end{tabular}

PB: Proteína bruta (CP: Crude protein); MS: Matéria seca (DM: Dry matter).

Médias na mesma linha, seguidas de letras diferentes, diferem entre si $(P<0,05)$ pelo teste Tukey.

Means within a row, followed by different letters, differ $(P<0.05)$, Tukey test.

de proteína na dieta. Resultados similares foram reportados por Pascoal et al. (2000), que analisaram o consumo de MS, o ganho de peso e a conversão alimentar de bezerros de corte desmamados aos 66 dias de idade, alimentados com 13, 15, 17 e 19\% de PB na dieta e não observaram efeitos significativos dos níveis de proteína dobre o consumo de MS.

A média de consumo de ração por animal por dia deste estudo foi de 0,284 kg MS, que é 25,85\% abaixo da relatada por Almeida Jr. (2002), de 0,383 kg MS/ dia; 33,65\% inferior à obtida por Garcia (2002), de 0,427 kg MS/dia; e 41\% menor à observada por Neres et al. (2001a), de 0,481 kg MS/dia, em cordeiros Suffolk em creep feeding, abatidos com 28 a 32 kg de peso vivo aos 62,6 dias de idade. Provavelmente, o menor consumo médio de ração apresentado pelos cordeiros neste experimento esteja relacionado à ingestão diária de leite, embora neste experimento as variáveis produção de leite pela ovelha e ingestão diária de leite pelos cordeiros não tenham sido avaliadas, refletindo a grande importância de se quantificálas em trabalhos futuros, uma vez que o leite participa positivamente no desempenho dos cordeiros. Silva et al. (2002) concluíram que a contribuição do leite no 
ganho de peso dos cordeiros é fundamental até o pico de lactação das mães e destacaram a importância da suplementação alimentar após o primeiro mês de vida. Em experimentos anteriores com o mesmo rebanho, Garcia (2002) verificou média de produção de leite pelas ovelhas de 1,789 kg por dia. Do mesmo modo, Silva et al. (2002) observaram média de 2,3 kg de leite por dia na terceira e quarta semanas de lactação.

O ganho médio diário influenciou a idade ao abate (Figura 1), embora esta variával não tenha sido afetada pelos tratamentos. Houve efeito significativo $(\mathrm{P}<0,05)$ para ganho médio diário, considerando-se o efeito fixo da ração e a covariável idade de abate, em função dos níveis de proteína.

Não houve diferença significativa entre os tratamentos com 15 e $20 \%$ PB para ganho médio diário. A ração contendo $25 \%$ de $\mathrm{PB}$ foi a que proporcionou maior ganho de peso diário (0,410 kg). O NRC (1985) recomenda para cordeiros com potencial de crescimento moderado, pesando de 10 a $30 \mathrm{~kg}$, aproximadamente $17 \%$ de PB e 2,8 Mcal EM/kg MS para ganho médio diário de $0,200 \mathrm{~kg}$.

Os resultados obtidos neste estudo corroboram o experimento de Fluharty \& McClure (1997), que observaram ganhos médios diários de 0,299 e 0,370 kg, em cordeiros Hampshire $\mathrm{x}$ Targhee desmamados precocemente e mantidos em confinamento recebendo rações contendo nível normal de proteína, segundo recomendação do NRC (1985), e nível elevado de proteína (25\% a mais da recomendação NRC, 1985), indicando superioridade para a ração com maiores níveis de PB.

Zundt et al. (2002) testaram níveis crescentes de proteína e energia $(12,16,20,24 \%$ de PB e 2,75 Mcal $\mathrm{EM} / \mathrm{kg} \mathrm{MS}$ ) na dieta de cordeiros confinados aos cinco meses de idade com peso médio de $30 \mathrm{~kg}$ e registraram ganhos médios de 0,154; 0,160; 0,166 e 0,172 kg/dia, respectivamente, demonstrando resposta positiva no desempenhoàmedidaquese aumentaram os níveis protéicos, mesmo nos cordeiros em idade mais avançada que os deste experimento, porém com desempenho inferior.

A idade média de abate de 64,4 dias deste estudo foi próxima àquelas obtidas por Almeida Jr. (2002), Garcia (2002), Neres et al. (2001a) e Garcia et al. (2000), de 62,48; 63,33; 62,00 e 63,22 dias, respectivamente, em condições experimentais semelhantes.

Constam na Figura 1 as regressões polinomiais dos níveis de 15; 20 e 25\% de proteína bruta para ganho médio diário dos cordeiros.
Os resultados das características referentes aos pesos das carcaças e aos rendimentos médios de carcaça quente e carcaça fria, ao rendimento verdadeiro e às perdas por resfriamento, de acordo com os níveis protéicos da dieta, encontram-se na Tabela 4. As variáveis analisadas não apresentaram diferenças significativas entre os tratamentos $(\mathrm{P}>0,05)$.

Os pesos médios entre os tratamentos para carcaça quente e fria deste experimento foram de 13,94 e 13,39 kg, respectivamente, e atendem aos padrões preconizados por Silva Sobrinho (2001) para cordeiros abatidos com 28 a $29 \mathrm{~kg}$ de PV.

Os pesos de carcaça quente e fria deste estudo foram similares aos observados por Almeida Jr. (2002), de 13,35 kg para peso de carcaça quente e 12,96 kg para peso de carcaça fria, ao avaliar a substituição do milho seco pela silagem de grãos úmidos de milho na alimentação de cordeiros criados e terminados em

Tabela 4 - Médias e coeficientes de variação (CV\%) de características de carcaça de cordeiros Suffolk alimentados com três níveis de proteína bruta

Table 4 - Mean and coefficients of variation (CV\%) of carcass traits of lambs fed three crude protein levels

\begin{tabular}{|c|c|c|c|c|}
\hline \multirow[t]{2}{*}{$\begin{array}{l}\text { Variável } \\
\text { Variable }\end{array}$} & \multicolumn{3}{|c|}{$\begin{array}{c}\text { Nível de proteína (\% PB) } \\
\text { Protein level }(\% \text { CP) }\end{array}$} & \multirow[t]{2}{*}{$\begin{array}{l}\text { CV } \\
(\%)\end{array}$} \\
\hline & 15 & 20 & 25 & \\
\hline $\begin{array}{l}\text { Peso vivo final }(\mathrm{kg}) \\
\text { Final body weight }(\mathrm{kg})\end{array}$ & $27,99^{a}$ & $28,72^{\mathrm{a}}$ & $28,42^{\mathrm{a}}$ & 1,98 \\
\hline $\begin{array}{l}\text { Peso vivo ao abate }(\mathrm{kg}) \\
\text { Slaughter weight }(\mathrm{kg})\end{array}$ & $26,00^{\mathrm{a}}$ & $26,83^{a}$ & $26,28^{a}$ & 2,55 \\
\hline $\begin{array}{l}\text { Peso de corpo } \\
\text { vazio }(\mathrm{kg}) \\
\text { Empty body weight }(\mathrm{kg})\end{array}$ & $23,58^{a}$ & $24,33^{a}$ & $24,29^{a}$ & 2,77 \\
\hline $\begin{array}{l}\text { Peso da carcaça } \\
\text { quente }(\mathrm{kg})\end{array}$ & $13,63^{\mathrm{a}}$ & $14,08^{\mathrm{a}}$ & $14,11^{\mathrm{a}}$ & 4,15 \\
\hline $\begin{array}{l}\text { Hot carcass weight }(\mathrm{kg}) \\
\text { Peso da carcaça } \\
\text { fria }(\mathrm{kg})\end{array}$ & $13,16^{\mathrm{a}}$ & $13,48^{a}$ & $13,54^{\mathrm{a}}$ & 3,90 \\
\hline $\begin{array}{l}\text { Cold carcass weight }(\mathrm{kg}) \\
\text { Rendimento de carcaça } \\
\text { quente }(\%)\end{array}$ & $52,37^{a}$ & $52,48^{\mathrm{a}}$ & $53,67^{a}$ & 3,53 \\
\hline $\begin{array}{l}\text { Hot carcass dressing (\%) } \\
\text { Rendimento de carcaça } \\
\text { fria }(\%)\end{array}$ & $50,60^{\mathrm{a}}$ & $50,23^{\mathrm{a}}$ & $51,51^{\mathrm{a}}$ & 3,42 \\
\hline $\begin{array}{l}\text { Cool carcass dressing (\%) } \\
\text { Rendimento verdadeiro (\% } \\
\text { Biological dressing (\%) }\end{array}$ & $57,73^{\mathrm{a}}$ & $57,87^{a}$ & $58,02^{a}$ & 2,18 \\
\hline $\begin{array}{l}\text { Perda no resfriamento (\%) } \\
\text { Cooling losses (\%) }\end{array}$ & $3,40^{\mathrm{a}}$ & $4,28^{\mathrm{a}}$ & $4,01^{\mathrm{a}}$ & 21,51 \\
\hline
\end{tabular}

Médias na mesma linha, seguidas de letras diferentes, não diferem entre si $(P>0,05)$ pelo teste Tukey.

Means within a row, followed by different letters, do not differ $(P<0.05)$, Tukey test. 


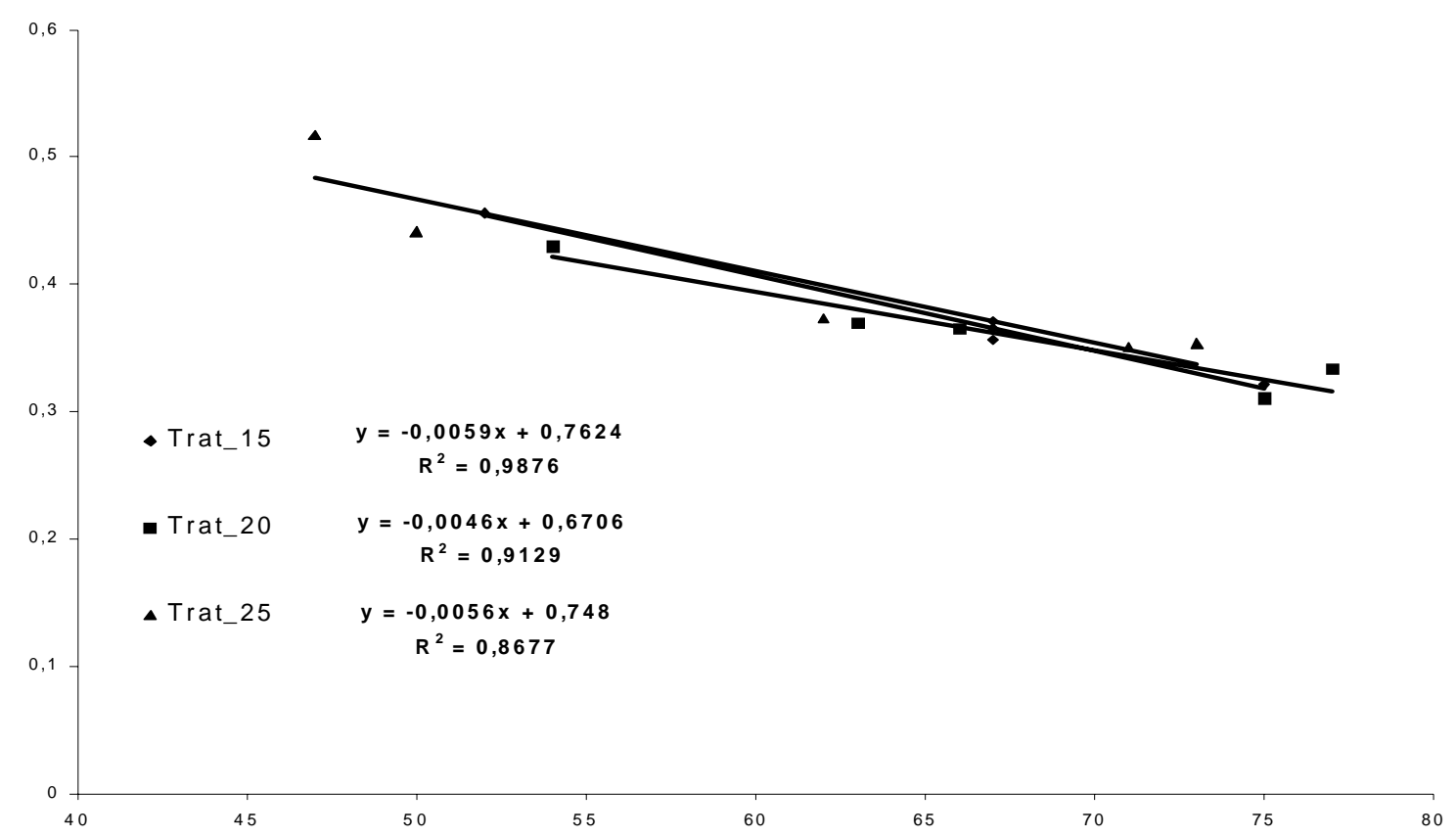

Figura 1 - Ganho médio diário $(\mathrm{kg})$ dos cordeiros de acordo com os níveis de proteína (15, 20 e 25\% PB) e a idade ao abate.

Figure 1 - Daily body weight gain $(\mathrm{kg})$ and slaughter age of lambs fed three protein levels (15, 20, and 25\% CP).

creep feeding e abatidos aos $28 \mathrm{~kg}$ de PV. Foram próximos, no entanto, aos obtidos por Neres et al. (2000), que estudaram o desempenho, os pesos e os rendimentos de cordeiros Suffolk alimentados em creep feeding, utilizando rações isoprotéicas (20\% PB) e isoenergéticas (2,9 Mcal EM/kg MS) e obtiveram peso de carcaça quente de $13,3 \mathrm{~kg}$ e peso de carcaça fria de $12,9 \mathrm{~kg}$ para o abate com 26 a $28 \mathrm{~kg}$ de peso vivo.

Ponnampalam et al. (2003) avaliaram os efeitos do nível protéico sobre as características de carcaça de cordeiros confinados e observaram peso de carcaça quente de 13,7 kg para o abate com $32 \mathrm{~kg}$ de PV, próximo aos resultados deste estudo. Entretanto, a idade média de abate foi de 180 dias, bem superior à encontrada neste experimento.

Neste trabalho, foram obtidos índices de 52,85\% para rendimento de carcaça quente; $50,78 \%$ de rendimento de carcaça fria; e 57,87\% de rendimento verdadeiro, que foram equivalentes aos verificados por Garcia (2002), Almeida Jr. (2002) e Neres et al. (2001b) em cordeiros criados e terminados em creep feeding. Os rendimentos foram próximos também aos registrados por Zundt et al. (2003), de 54,46\% para rendimento de carcaça quente, 48,37\% para carcaça fria e de $53,55 \%$ de rendimento verdadeiro, em cordeiros em confinamento.

Os gastos com alimentação animal certamente constituem o principal componente do custo total de produção, de modo que a proteína bruta torna-se o ingrediente mais oneroso da ração. Portanto, é de grande importância atentar para o custo/benefício, resultante da inclusão de níveis crescentes de proteína na dieta dos cordeiros.

As rações foram formuladas com ingredientespadrão, ressaltando-se que o milho, o farelo de soja e o farelo de trigo apresentavam custos mais elevados para o nível de 25\% PB. A ração com 15\% PB teve custo total $21 \%$ inferior ao da ração com $20 \%$ de PB, que por sua vez apresentou custo total $28,5 \%$ abaixo da ração com 25\% de $\mathrm{PB}$.

$\mathrm{Na}$ análise econômica das rações experimentais, foram considerados os preços médios de carcaça fria de cordeiro e dos ingredientes da ração, em reais (R\$), vigentes no primeiro semestre de 2004 (Tabela 5).

Os resultados deste estudo corroboram os obtidos por Zundt et al. (2002), que, ao avaliarem o desempenho de cordeiros em confinamento alimentados com 
níveis crescentes de proteína bruta na ração $(12,16$, 20 e 24\% PB), verificaram retorno econômico tanto para machos como para fêmeas nos quatro níveis de PB. Entretanto, com a elevação dos teores de proteína, houve decréscimo na margem de lucro.

A análise econômica da produção de carne de cordeiros foi realizada a fim de se verificar a viabilidade do uso das rações com três níveis distintos de $\mathrm{PB}$, sem considerar os demais custos fixos e operacionais relativos à produção ovina (Tabela 6).

Os resultados econômicos por cordeiro foram próximos para os animais alimentados com 15 e $20 \%$ de PB na ração. O nível de $25 \%$ de $\mathrm{PB}$ proporcionou resultado econômico por cordeiro aproximadamente 4\% menor que os demais níveis. Entretanto, uma vez que a idade de abate foi positivamente influenciada pelos ganhos médios diários conforme os níveis crescentes de proteína bruta, a ração com $25 \%$ de PB promoveu peso de abate (28 kg) em menor tempo e, portanto, resultado econômico por cordeiro por dia 3,7 e 5,9\% melhor que os níveis de 15 e $20 \%$ de PB respectivamente.

Tabela 5 - Preços dos ingredientes e custos das rações experimentais

Table 5 - Ingredient price and diet costs

\begin{tabular}{|c|c|}
\hline $\begin{array}{l}\text { Produto } \\
\text { Product }\end{array}$ & $\begin{array}{c}\text { Preço (R\$/kg MO } \\
\text { Price }(R \$ / k g O M)\end{array}$ \\
\hline $\begin{array}{l}\text { Feno de tyfton } 85 \\
\text { Tyfton } 85 \text { hay }\end{array}$ & 0,35 \\
\hline $\begin{array}{l}\text { Farelo de soja } \\
\text { Soybean meal }\end{array}$ & 1,03 \\
\hline $\begin{array}{l}\text { Farelo de trigo } \\
\text { Wheat bran }\end{array}$ & 0,42 \\
\hline $\begin{array}{l}\text { Milho moído } \\
\text { Ground corn }\end{array}$ & 0,43 \\
\hline $\begin{array}{l}\text { Sal mineral } \\
\text { Mineral salt }\end{array}$ & 1,20 \\
\hline $\begin{array}{l}\text { Suplemento vitamínico } \\
\text { Vitamin supplement }\end{array}$ & 1,15 \\
\hline $\begin{array}{l}\text { Ração } \\
\text { Concentrate }\end{array}$ & $\begin{array}{c}\text { Custo (R\$/kg MS) } \\
\text { Cost }(R \$ / k g D M)\end{array}$ \\
\hline $\begin{array}{l}\text { Ração } 1 \text { (15\% PB) } \\
\text { Concentrate } 1 \text { (15\% CP) }\end{array}$ & 0,55 \\
\hline $\begin{array}{l}\text { Ração } 2(20 \% \text { PB) } \\
\text { Concentrate } 2(20 \% \text { CP) }\end{array}$ & 0,63 \\
\hline $\begin{array}{l}\text { Ração } 3(25 \% \text { PB) } \\
\text { Concentrate } 3(25 \% \text { CP) }\end{array}$ & 0,71 \\
\hline
\end{tabular}

PB: Proteína bruta (CP: Crude protein); MS: Matéria seca (DM: Dry matter).
Siqueira et al. (2001), em estudo com cordeiros desmamados aos 60 dias de idade com $12 \mathrm{~kg}$ de PV e confinados por 67 dias, destacaram que, em sistemas intensivos de produção de carne, é necessário que o material genético do rebanho tenha elevado potencial de crescimento para máxima redução do tempo de confinamento para alcançar o peso ideal de abate, que se situa na faixa de $28 \mathrm{~kg}$, tanto para machos como para fêmeas, por proporcionar melhor retorno econômico.

Neste trabalho, o uso do creep feeding para a alimentação dos cordeiros reduziu a idade de abate em 62,6 dias, em comparação à idade registrada por Siqueira et al. (2001); em 142,6 dias, em relação à obtida por Zundt et al. (2002), em raças tipo carne de diferentes grupos genéticos. A adoção do creep feeding para a alimentação de cordeiros é, portanto, uma técnica eficiente, que reduz a idade de abate e diminui os custos com alimentação, garantindo retorno econômico ao produtor em menor tempo.

Tabela 6 - Resultados econômicos obtidos com os diferentes níveis de proteína bruta $(\mathrm{PB})$ na ração de cordeiros em creep feeding

Table 6 - Economical analysis of feeding different levels of crude protein (CP) for lambs in creep feeding

\begin{tabular}{|c|c|c|c|}
\hline \multirow[t]{2}{*}{$\begin{array}{l}\text { Variável } \\
\text { Variable }\end{array}$} & \multicolumn{3}{|c|}{$\begin{array}{c}\text { Nível de proteína (\% PB) } \\
\text { Protein level (\% CP) }\end{array}$} \\
\hline & 15 & 20 & 25 \\
\hline $\begin{array}{l}\text { Preço da carcaça fria }(\mathrm{R} \$ / \mathrm{kg}) \\
\text { Price of cold carcass }(R \$ / \mathrm{kg})\end{array}$ & 7,00 & 7,00 & 7,00 \\
\hline $\begin{array}{l}\text { Peso da carcaça fria }(\mathrm{kg}) \\
\text { Cold carcass weight }(\mathrm{kg})\end{array}$ & 13,16 & 13,48 & 13,54 \\
\hline $\begin{array}{l}\text { Custo da ração MS }(\mathrm{R} \$ / \mathrm{kg}) \\
\text { Cost of concentrate DM }(R \$ / \mathrm{kg})\end{array}$ & 0,55 & 0,63 & 0,71 \\
\hline $\begin{array}{l}\text { Consumo total MS de } \\
\text { ração/cordeiro }(\mathrm{kg}) \\
\text { DM total intake/lamb }(\mathrm{kg})\end{array}$ & 12,92 & 14,20 & 17,63 \\
\hline $\begin{array}{l}\text { Idade ao abate (dias) } \\
\text { Slaughter age (days) }\end{array}$ & 65,60 & 67,00 & 60,60 \\
\hline $\begin{array}{l}\text { Receita bruta/ } \\
\text { cordeiro }(\mathrm{R} \$)\end{array}$ & 92,12 & 94,36 & 94,78 \\
\hline Gross income/lamb $(R \$)$ & & & \\
\hline $\begin{array}{l}\text { Custo de alimentação/ } \\
\text { cordeiro }(\mathrm{R} \$) \\
\text { Feed cost/lamb }(R \$)\end{array}$ & 7,10 & 8,95 & 12,52 \\
\hline $\begin{array}{l}\text { Resultado econômico/ } \\
\text { cordeiro (R\$) } \\
\text { Net income/lamb }(R \$)\end{array}$ & 85,02 & 85,41 & 81,60 \\
\hline $\begin{array}{l}\text { Resultado econômico/ } \\
\text { cordeiro/dia (R\$) } \\
\text { Net income/day/lamb }(R \$)\end{array}$ & 1,30 & 1,27 & 1,35 \\
\hline
\end{tabular}




\section{Conclusões}

Para criação e terminação de cordeiros mestiços Suffolk em creep feeding, a ração deve ser balanceada com $25 \%$ de proteína bruta, pois esse nível proporcionou maior ganho de peso médio diário e não interferiu nas características de carcaças.

\section{Literatura Citada}

ALMEIDA JR., G.A. Silagem de grãos úmidos de milho na ração de cordeiros em creep feeding. Botucatu: Universidade Estadual Paulista, 2002. 61p. Dissertação (Mestrado em Zootecnia) - Universidade Estadual Paulista, 2002.

BUENO, M.S.; CUNHA, E.A.; SANTOS, L.E. et al. Características de carcaça de cordeiros Suffolk abatidos em diferentes idades. Revista Brasileira de Zootecnia, v.29, n.6, p.1803-1810, 2000.

CARVALHO, S.; PIRES, C.C.; PERES, C.Z. Exigências líquidas de energia para ganho de peso de cordeiros. In: REUNIÃO ANUAL DA SOCIEDADE BRASILEIRA DE ZOOTECNIA, 35., 1998, Botucatu. Anais... Botucatu: Sociedade Brasileira de Zootecnia, 1998. p.104.

FLUHARTY, F.L.; McCLURE, K.E. Effects of dietary energy intake and protein concentration on performance and visceral organ mass in lambs. Journal of Animal Science, v.75, p.604-610, 1997.

GARCIA, C.A.; MONTEIRO, A.L.G.; NERES, M.A. et al. Desempenho de cordeiros com diferentes níveis de energia em creep feeding. In: REUNIÃO ANUAL DA SOCIEDADE BRASILEIRA DE ZOOTECNIA, 37., 2000, Viçosa, MG. Anais... Viçosa, MG: Sociedade Brasileira de Zootecnia/ Gnosis, [2000]. Nutrição de Ruminantes, 0930. CD-ROM.

GARCIA, C.A. Níveis de energia na ração de cordeiros em creep feeding. Botucatu: Universidade Estadual Paulista, 2002. 60p. Tese (Doutorado em Zootecnia) - Universidade Estadual Paulista, 2002.

MATOS, M.S.; MATOS, P.F. Laboratório Clínico MédicoVeterinário. 2.ed. Rio de Janeiro: Atheneu, 1988. 238p.

MEHEREZ, H.Z.; ORSKOV, E.R. Protein degradation and optimum urea concentration in cereal based diets for sheep. British Journal of Nutrition, v.40, n.2, p.437-345, 1978.

MILTON, C.T.; BRANDT JR., R.T.; TITGEMEYER, E.C. Effects of dietary nitrogen source and concentration in high-grain diets on finishing steer performance and nutrients digestion. Journal of Animal Science, v.75, p.2813-2823, 1997.

MONTEIRO, A.L.G.; NERES, M.A.; GARCIA, C.A. et al. Avaliação da compacidade e da composição tecidual das carcaças de cordeiros alimentados em creep feeding. REUNIÃO ANUAL DA SOCIEDADE BRASILEIRA DE ZOOTECNIA, 37., 2000, Viçosa, MG. Anais... Viçosa, MG: Sociedade Brasileira de Zootecnia/Gnosis, [2000]. Nutrição de Ruminantes, 0929. CD-ROM.

NATIONAL RESEARCH COUNCIL - NRC. Nutrient requirements of sheep. Washington, D.C.: National Academy Press, 1985. 99p.

NATIONAL RESEARCH COUNCIL - NRC. Nutrient requirements of beef cattle. 7.ed. Washington, D.C.: National Academy Press, 1996. 242p.
NERES, M.A. Níveis de feno de alfafa (Medicago sativa L.) e forma física da ração no desempenho e características de carcaça de cordeiros em “creep feeding”. Botucatu: Universidade Estadual Paulista, 2000.53 p. Tese (Doutorado em Zootecnia) - Universidade Estadual Paulista, 2000.

NERES, M.A.; GARCIA, C.A.; MONTEIRO, A.L.G. et al. Desempenho, peso e rendimentos de carcaças de cordeiros criados em creep feeding. REUNIÃO ANUAL DA SOCIEDADE BRASILEIRA DE ZOOTECNIA, 37., 2000, Viçosa, MG. Anais... Viçosa, MG: Sociedade Brasileira de Zootecnia/ Gnosis, [2000]. Nutrição de Ruminantes, 0934. CD-ROM.

NERES, M.A.; GARCIA, C.A.; MONTEIRO, A.L.G. et al. Níveis de feno de alfafa e forma física da ração no desempenho de cordeiros em creep feeding. In: Revista Brasileira de Zootecnia, v.30, n.3, p.941-947, 2001a (Supl. 1).

NERES, M.A.; MONTEIRO, A.L.G.; GARCIA, C.A. et al. Forma física da ração e pesos de abate nas características de carcaça de cordeiros em creep feeding. In: Revista Brasileira de Zootecnia, v.30, n.3, p.948-954, 2001b (Supl. 1).

PASCOAL, L.L.; EIFERT, E.C.; RESTLE, J. Nível de proteína bruta para bezerros de corte desmamados aos 66 dias de idade. Revista Brasileira de Zootecnia, v.29, n.5, p.1537-1544, 2000.

PONNAMPALAM, E.N.; HOSKING, B.J.; EGAN, A.R. Rate of carcass componentes gain, carcass characteristics, and muscle longissimus tenderness in lambs fed dietary protein sources with a low quality roughage diet. Meat Science, v.63, p.143-149, 2003.

REIS, W.; JOBIM, C.C.; MACEDO, F.A.F. et al. Características da carcaça de cordeiros alimentados com dietas contendo grãos de milho conservados em diferentes formas. In: REUNIÃO ANUAL DA SOCIEDADE BRASILEIRA DE ZOOTECNIA, 37., 2000, Viçosa, MG. Anais... Viçosa, MG: Sociedade Brasileira de Zootecnia/Gnosis, [2000]. Nutrição de Ruminantes, 0796. CD-ROM.

STATISTICAL ANALYSES SYSTEM - SAS. User's guide: statistics. 5.ed. Cary: 1985. 955p.

SILVA, J.J.; COSTA, C.; MONTEIRO, A.L.G. et al. Contribuição do leite de ovelhas Suffolk no desempenho dos cordeiros em dois sistemas de produção. In: REUNIÃO ANUAL DA SOCIEDADE BRASILEIRA DE ZOOTECNIA, 39., 2002, Recife. Anais... Recife: Sociedade Brasileira de Zootecnia, [2002]. Manejo e Reprodução [03sbz190.pdf]. CD-ROM.

SILVA SOBRINHO, A.G. Aspectos quantitativos e qualitativos da produção de carne ovina. A produção animal na visão dos brasileiros. In: REUNIÃO ANUAL DA SOCIEDADE BRASILEIRA DE ZOOTECNIA, 38., 2001, Piracicaba. Anais... Piracicaba: Sociedade Brasileira de Zootecnia, [2001]. Ovinocultura/Caprinocultura [Semi27.PDF]. CD-ROM.

SIQUEIRA, E.R. Manejo de matrizes em rebanhos produtores de carne. A produção animal na visão dos brasileiros. In: REUNIÃO ANUAL DA SOCIEDADE BRASILEIRA DE ZOOTECNIA, 38., 2001, Piracicaba. Anais... Piracicaba: Sociedade Brasileira de Zootecnia, [2001]. Ovinocultura/ Caprinocultura [Semi28.PDF]. CD-ROM.

SIQUEIRA, E.R.; SIMÕES, C.D.; FERNANDES, S. Efeito do sexo e do peso ao abate sobre a produção de cordeiros. I. Velocidade de crescimento, caracteres quantitativos da carcaça, pH da carne e resultado econômico. Revista Brasileira de Zootecnia, v.30, n.3, p.844-848, 2001.

SUSIN, I.; ROCHA, M.H.M.; PIRES, A.V. Efeito do uso de bagaço de cana-de-açúcar in natura ou hidrolisado sobre o desempenho de cordeiros confinados. In: REUNIÃO ANUAL 
DA SOCIEDADE BRASILEIRA DE ZOOTECNIA, 37., 2000, Viçosa, MG. Anais... Viçosa, MG: Sociedade Brasileira de Zootecnia/Gnosis, [2000]. Nutrição de Ruminantes, 0786. CD-ROM.

ZUNDT, M.; MACEDO, F.A.F.; MARTINS, E.N. et al. Características de carcaça de cordeiros terminados em confinamento com dietas contendo diferentes níveis protéicos. Ciência Rural, v.33, n.3, p.565-571, 2003.

ZUNDT, M.; MACEDO, F.A.F.; MARTINS, E.N. Desempenho de cordeiros alimentados com diferentes níveis protéicos. Revista Brasileira de Zootecnia, v.31, n.3, p.1307-1314, 2002.
ZUNDT, M.; MACEDO, F.A.F.; MEXIA, A.A. et al. Digestibilidade total aparente in vivo de dietas contendo diferentes níveis protéicos em ovinos. In: REUNIÃO ANUAL DA SOCIEDADE BRASILEIRA DE ZOOTECNIA, 38., 2001, Piracicaba. Anais... Piracicaba: Sociedade Brasileira de Zootecnia, [2001]. Nutrição de Ruminantes [6-1053.PDF]. CD-ROM.

Recebido em: 01/12/04

Aceito em: 04/08/05 